\title{
Correction to: Common ancestry of heterodimerizing TALE homeobox transcription factors across Metazoa and Archaeplastida
}

Sunjoo Joo ${ }^{1+}$, Ming Hsiu Wang ${ }^{1+}$, Gary Lui ${ }^{1}$, Jenny Lee ${ }^{1}$, Andrew Barnas ${ }^{1}$, Eunsoo Kim², Sebastian Sudek ${ }^{3}$, Alexandra Z. Worden ${ }^{3,4}$ and Jae-Hyeok Lee ${ }^{1 *}$

\section{Correction to: BMC Biology}

\section{https://doi.org/10.1186/s12915-018-0605-5}

Upon publication of the original article [1], it was noticed that Alexandra Z. Worden's affiliation is not complete. The full affiliation information for Alexandra Z. Worden can be found below and in the complete affiliation list of this Correction article.

- Ocean EcoSystems Biology Unit, RD3 GEOMAR Helmholtz Centre for Ocean Research Kiel, Kiel, Germany.

- Monterey Bay Aquarium Research Institute, 7700 Sandholdt Rd., Moss Landing, CA 95039, USA.

\footnotetext{
Author details

${ }^{1}$ Department of Botany, University of British Columbia, 6270 University Blvd, Vancouver, BC V6T 1Z4, Canada. ${ }^{2}$ Division of Invertebrate Zoology and Sackler Institute for Comparative Genomics, American Museum of Natural History, 200 Central Park West, New York, NY 10024, USA. ${ }^{3}$ Monterey Bay Aquarium Research Institute, 7700 Sandholdt Rd, Moss Landing, CA 95039, USA. ${ }^{4}$ Ocean EcoSystems Biology Unit, RD3 GEOMAR Helmholtz Centre for Ocean Research Kiel, Kiel, Germany.
}

Published online: 09 January 2020

\section{Reference}

1. Joo, et al. Common ancestry of heterodimerizing TALE homeobox

transcription factors across Metazoa and Archaeplastida. BMC Biology. 2018; 16:136 https://doi.org/10.1186/s12915-018-0605-5.

The original article can be found online at https://doi.org/10.1186/s12915018-0605-5

* Correspondence: jae-hyeok.lee@botany.ubc.ca

†Sunjoo Joo and Ming Hsiu Wang contributed equally to this work.

${ }^{1}$ Department of Botany, University of British Columbia, 6270 University Blvd, Vancouver, BC V6T 1Z4, Canada

Full list of author information is available at the end of the article

(c) The Author(s). 2020 Open Access This article is distributed under the terms of the Creative Commons Attribution 4.0 International License (http://creativecommons.org/licenses/by/4.0/), which permits unrestricted use, distribution, and reproduction in any medium, provided you give appropriate credit to the original author(s) and the source, provide a link to the Creative Commons license, and indicate if changes were made. The Creative Commons Public Domain Dedication waiver (http://creativecommons.org/publicdomain/zero/1.0/) applies to the data made available in this article, unless otherwise stated. 